\title{
Evolution of U.S. Presidential Discourse over 230 Years: A Psycholinguistic Perspective
}

\author{
Xueliang $\mathrm{Chen}^{1} \& \mathrm{Jie} \mathrm{Hu}^{1}$ \\ ${ }^{1}$ Department of Linguistics and Translation, School of International Studies, Zhejiang University, Hangzhou, \\ China \\ Correspondence: Jie Hu, Department of Linguistics and Translation, School of International Studies, Zhejiang \\ University, Hangzhou, 310058, China. ORCID: http://orcid.org/0000-0003-2219-2587 E-mail: huj@zju.edu.cn
}

Received: April 28, 2019 Accepted: May 18, 2019 Online Published: June 12, 2019

doi:10.5539/ijel.v9n4p28 URL: https://doi.org/10.5539/ijel.v9n4p28

\begin{abstract}
Much of recent research on U.S presidential discourse has focused on the nexus between language forms and their underlying social processes and psychological states. However, little work has been done to shed light on how these latent characteristics have evolved over time. This study investigated the evolution of three psychological states (authenticity, affect, and time orientation) underlying U.S. presidential discourse over approximately 230 years (1789-2016). Based on one of the most comprehensive corpora of presidential speech transcripts, Linguistic Inquiry and Word Count (LIWC) 2015, a text analysis software, was utilized to explore these psychological states. To see the overall trend of these states across U.S. presidential history as a whole, initial analysis was based on LIWC indices, which showed that, 1) overall, authenticity level is on a steady increase in U.S. presidential discourse; 2) in the presidents' speeches, positive emotions invariably outweigh negative emotions, and both types of emotion remain relatively constant in the long run; 3 ) the discourse of "focus on present" consistently outweighs the discourse of "focus on future", which outweighs the discourse of "focus on past". To see whether the general trend holds across different parties, a series of independent samples t-tests were first performed to check for significant difference. The results indicated that in all the three psychological states, there was no significant difference between the Democratic presidents and the Republican presidents, and that the trend in different parties is in agreement with the overall trend. Subsequent visualization of the LIWC indices according to party generally corroborated these results, with only one exception: authenticity levels are on a steady increase in the discourse of the Democratic presidents, but in the Republican presidents, there was a sharp increase in recent years.
\end{abstract}

Keywords: LIWC 2015, evolution, psychological states, U.S. presidential discourse

\section{Introduction}

The U.S. presidents are among the most studied political figures in the world, partly because the high-profile nature of the presidency arouses strong interest among the public, and partly because understanding how the presidents present themselves can generate important insights into their personalities and policies (Biria \& Mohammadi, 2012). One popular way to study the presidents is to analyze their discourse, both written and spoken, as a means to explore the social and psychological processes that underlie their linguistic manifestations.

The existing studies on U.S. presidential discourse has culminated in a mature field of academic inquiry, with a plethora of books and journal articles already published on this topic. These studies represent a wide array of perspectives, covering such aspects as the linguistic features of presidential discourse and how they evolve over time (Kubat \& Cech, 2016; Chen, Yan, \& Hu, 2019; Xiao, Li, \& Chen, 2019), the role of such discourse in crafting public personas (Benoit, 2006; Ponterotto, 2018), the framing of collective national identity and the expression of social values (Dunmire, 2005; Chen \& Hu, 2018; Hu \& Wei, 2018), etc. Utilizing archival data of presidential discourse to examine the psychology of different presidents has also received ample scholarly attention, usually based on the assumption that people's language use could reflect underlying psychological states or personalities. For example, Thoemmes and Conway (2007) used a measure known as integrative complexity (IC) to study the thinking complexity of 41 U.S. presidents. They found that the presidents' IC tends to be higher at the beginning of their first term and begins to drop near the end. Their results also suggested that the presidents' overall IC was partially accounted for by chronic differences between presidents' complexity 
levels. In a comparative study on individual differences between the 2004 presidential and vice-presidential candidates, it was shown that President George Bush displays more openness and emotionality, and that he tends to focus more on the future than on the past (Slatcher, Chung, Pennebaker, \& Stone, 2007). Recent studies on Trump's discourse indicated that he has a populist propensity (Schoor, 2017) and is associated with an authoritarian ideology (Choma \& Hanoch, 2017).

However, little research has been conducted to explore how the psychological states underlying U.S. presidential discourse evolve over time. Even though some diachronic studies do exist, they generally focus on the linguistic features or the social functions of language use, instead of focusing on the underlying psychological states. As linguistics and psychological science become increasingly intertwined, it is both imperative and interesting to know what the presidents are "thinking" in the back of their mind, which might provide us with some essential information about their personality traits, the way they govern, and how they made the kind of decisions that impact people's lives.

Therefore, to explore the psychological states of U.S. presidents through their discourse and their evolution over time, the following research questions are formulated:

1) How do the psychological states underlying U.S. presidential discourse change over time, in terms of authenticity, affect, and time orientation?

2) Do these changes hold with U.S. presidents from different political parties? What are the similarities and differences between these psychological states underlying their discourse?

\section{Literature Review}

Popular and scholarly interest in U.S. presidential discourse has had a long history, dating back as early as the late 18th century, when the country first gained independence from colonial rule. Over two centuries later, a unique field of academic inquiry has taken shape. Though historical documents offer compelling evidence that explorations into U.S. presidential discourse have lasted for centuries, research in the modern sense only began in the past several decades. Within this period, publications addressing this topic have witnessed an exponential increase, and introduced diverse perspectives. A brief overview of the literature suggests that two major lines of research have characterized the existing studies.

One line of research is primarily concerned with the rhetorical aspects of the presidents' language use, namely, how different language forms are presented and organized in presidential discourse at the lexical, syntactic, and discourse levels. For example, a number of studies on pronoun use have reached a general consensus that "we" is used more often than "I" in different types of presidential discourse (Field, 2011; Halmari, 2008), despite the fact that some presidents seem to deviate from this norm (Ahmadian, Azarshahi, \& Paulhus, 2017). The presidents who score high on political conservatism have also been shown to use a greater proportion of nouns in their major speeches compared to those who are less conservative (Cichocka, Bilewicz, Jost, Marrouch, \& Witkowska, 2016). On the whole, the discourse of American presidents has taken on an increasingly more communicative style, which is attributed to the emergence of and intimacy between radio and television (Widmer, 2006). Lim (2008) also provided evidence that there is a tendency toward syntactic and semantic simplification in presidential discourse from George Washington to George Bush. This finding is echoed and complemented by Savoy (2017), whose study on 43 U.S. presidents' State of the Union messages shows that as time elapses, the vocabulary used in presidential discourse becomes less complex, the percent of big words decreases, and the sentences become shorter. Wilson (2015) presented a pragmatic analysis of six U.S. presidents' language (from John F. Kennedy to Barack Obama). His study showed that the presidents are adept at mobilizing various rhetorical techniques to achieve desired objectives, such as obfuscation, misdirection, and the use of metaphor or ambiguity. In comparison to these studies, which approach the discourse of different U.S. presidents as a whole, studies on individual presidents have also provided some important insights into the presidents' language use. In a recent study aimed to verify hypothesized linguistic change in President Donald Trump, Coutanche and Paulus (2018) reported that from 2011 to 2017, the use of filler words experienced a sharp increase in Trump's discourse Similarly, over the course of President Ronald Reagan's presidency, there was an increase in his use of conversational fillers (e.g., "um," "uh", etc.) and non-specific nouns (e.g., "something") (Berisha, Wang, LaCross, \& Liss, 2015). Research on Obama's discourse has revealed that in the case of spontaneous remarks, Obama tends to use introductory words and phrases prior to delivering his speeches, and that he also uses a higher percentage of first-person singular pronouns in this type of speech than in other prepared remarks (O’Connell, Kowal, Sabin, Lamia, \& Dannevik, 2010).

A second line of research concerns the social or psychological aspects of presidential discourse, wherein the functions of language, language users and language use contexts are emphasized rather than language itself. It 
has been long established, for example, that presidential discourse can be used as an instrument of control (Hodge \& Kress, 1993) and serve as a strategy of legitimization to justify certain social practices (Reyes, 2011). Also, different discursive strategies can be used in political discourse to project the president's vision of the future and implicate the citizenry in that vision (Dunmire, 2005). A particularly fruitful area of research on the social functions of presidential language has centered around the State of the Union Address, where presidential discourse studies have been related to the expression of diplomatic and geopolitical constructs (Flint, Adduci, Chen, \& Chi, 2009), the establishment of legislative agendas (Moen, 1988; Chen, Zhang, Wei, \& Hu, 2019), and the effect of such discourse on the opposition party and the media (Bradshaw, Coe, \& Neumann, 2014; Panagopoulos, 2011), etc. Studies on the psychology of language use has proceeded in a similar direction. For example, a series of studies based on SOTU messages have sought to measure the integrative complexity of U.S. presidents (Thoemmes et al., 2007) or the characteristics of charismatic leadership (Wasike, 2017). Dyson and Preston (2006) studied the use of analogies in the U.S. presidents' foreign policy decision making, and found that a majority of the analogies used by low-complexity presidents were non-sophisticated, while those used by high-complexity presidents were more sophisticated. Slatcher et al. (2007) relates the discourse of President George W. Bush and other political candidates to their personalities and psychological states. They found that their linguistic styles are variously associated with cognitive complexity, femininity, depression, aging, presidentiality, and honesty. In another study analyzing President Trump's language during debates, Jordan, Pennebaker and Ehrig (2018) concluded that Trump's language was low in analytic thinking or formal thinking, but high in negative emotional tone and authenticity, in direct opposition to the findings regarding his opponents. Building on their finding, Jordan, Sterling, Pennebaker and Boyd (2019) set out to measure the long-term trends of politics worldwide. Their results further demonstrated that over America's 200-plus years of history, presidential discourse displays a tendency to decrease in analytic thinking and increase in clout, two psychological indices that are part of the Linguistic Inquiry and Word Count default dictionaries. In explaining this phenomenon, they point to the emergence of an increasingly rhetorical presidency and the recent rise of populism.

One thing that is noteworthy is that few studies focus exclusively on linguistic, sociological or psychological aspects of presidential discourse. Language use, as it occurs in a particular social context and is exercised by a particular individual or individuals, is fundamentally a social practice, tinted by individual personality traits. Both linguistic knowledge and pragmatic knowledge will have to be brought to bear on achieving targeted goals. Therefore, one is cautioned not to draw a "clear" distinction between them as if such a demarcation did exist. The previous distinction is meant only to present a clear picture of the existing studies.

\section{Methodology}

\subsection{Materials}

A total of 44 corpora comprising the speech transcripts of 44 U.S. presidents (from George Washington to Barack Obama) were used in this study as our research materials. The corpora were selected from the Grammar Lab (www.grammarlab.com), a website dedicated to advancing linguistic research, where several pre-edited corpora are publicly available for research purposes. The speech transcripts cover every president since the country gained independence in 1776, with the only exception of the sitting U.S. President Donald Trump, because his presidency has not yet come to a close. The transcripts are also comprehensive in scope, incorporating all possible types of speeches, such as inaugural addresses, campaign speeches, State of the Union Address, press releases, among others. In the aggregate the corpora amount to 3587525 words, and the number of words in each sub-corpus is also specified (See Appendix A). Appendix A also presents the basic information of the corpora, including the names of all 44 U.S. presidents, the code assigned to each president, their party affiliation, term in office, etc.

\subsection{Instrument}

Linguistic Inquiry and Word Count (LIWC) 2015, a text analysis software, was used in this study for analysis. Developed by social psychologist James W. Pennebaker at the University of Texas, LIWC was initially designed as an exploratory tool to study "the various emotional, cognitive, and structural components present in individuals' verbal and written speech samples" (Pennebaker, Boyd, Jordan, \& Blackburn, 2015, p. 8). As later psychological and linguistic theories developed, the software was refined several times and the latest version was released in 2015, namely, LIWC 2015. LIWC 2015 has an internal default dictionary that defines words according to their given categories. These categories comprise different groups of words that tap a particular domain (e.g., words denoting authenticity, positive emotion words, and linguistic dimensions). Incoming text files are processed according to their fitness with the pre-determined categories, thus providing the basis for 
linking linguistic features to underlying psychological states or processes. Before the software was released, its reliability and validity have been vigorously tested, with the results showing high internal reliability between different dimensions and high external validity (Pennebaker et al., 2015; Jin, Li, Chen, Li, \& Hu, 2015; Wei, Yang, Chen, \& Hu, 2018). Furthermore, LIWC has been widely applied in different fields, such as psychology, psychiatry, and linguistics. The promising findings in application make us confident to utilize this tool in the present study.

Among its many functions, LIWC defines several social and psychological processes that can be reflected in people's language use, such as analytic thinking, clout, authenticity, affect, power, and time orientation, among others. The focus of the present study will be on three psychological indices: authenticity, affect, and time orientations. Authenticity indicates the level of truthfulness in people's language, or how much of what an individual says or writes reflects their genuine thoughts. According to Pennebaker et al. (2015), authenticity is a "non-transparent" dimension in LIWC 2015, meaning that no single category of words directly indicates authenticity. Instead, authenticity is measured holistically based on a combination of relevant constructs, such as deception, exclusion, and anxiety, which can be embodied by specific words. For example, the frequency of articles, pronouns and prepositions in a text is closely related to deception, which is the antithesis of authenticity (Newman, Pennebaker, Berry, \& Richards, 2003). Affect relates to people's emotional state and is divided into positive emotions and negative emotions. Words that embody positive or negative emotions mainly comprise content words, such as verbs, adjectives and adverbs, because these words or word categories carry substantive information at the semantic level. The criteria for qualifying as positive or negative words are inherent in the software, which are based on previously published results and trials with large samples of texts. Examples of positive words include love, nice, sweet, etc., while negative words include hurt, ugly, nasty, etc. Time orientation is primarily concerned with people's attention to the temporality of events, including focus on past, focus on present, and focus on future. Words that embody time orientation are comparatively more obvious, appearing most often in the form of tensed verbs (e.g., talked, did, approached, etc.), adverbs (ago, now, soon, etc.) and modal auxiliaries (may, might, will, etc.).

These categories are strongly experiential in nature, that is, they rely heavily on people's real-world experiences, which then serve as subjective criteria to categorize newly met written or oral texts. In the initial design of LIWC, this is also how word categories were identified: by maximizing the agreement between different well-trained raters who were asked to evaluate the texts based on their own understanding. The difference between purely subjective criteria and those of LIWC 2015 is that the latter provides a more reliable index of the various constructs implicit in language forms, having been tested with large sample sizes and validated in numerous theoretical and empirical studies. In addition, the computerized analysis software makes it possible to process huge volumes of data at the same time, with greater stability and decreased measurement error, which make the use of LIWC 2015 especially appropriate to the current study.

\subsection{Procedure}

To explore the psychological states, all the 44 corpora are entered into LIWC 2015, which then automatically outputs a number of quantitative indices that are meant to measure different constructs. As has been briefly mentioned, only three psychological states are of concern in this study. Therefore, the indices related to these three constructs are selected and translated into a table format (See Appendix B).

The first step is to observe the overall trend of the three psychological states underlying U.S. presidential discourse over time. Toward this end, different graphs are plotted to provide a rough estimate of this trend, with 44 U.S. presidents placed on the horizontal axis and the corresponding psychological indices on the vertical axis. This step can help visualize the general tendency and the variations in the presidential discourse, thus making the evolutionary process crystal clear.

The second step is to further divide the presidents according to their party affiliation, which is meant to see whether the trend observed in the first step holds across different parties. Toward this end, a series of independent samples t-tests based on the LIWC indices were first performed to identify if any significant difference exists. Next, the same indices were used to plot another set of graphs, where the discourse of presidents from different parties are put on a common scale for comparison. This step will clarify the similarities and differences that exist between the presidents in their discourse. In addition, how the psychological states of the presidents from different parties contribute to the overall trend will be illuminated as well. 


\section{Results}

4.1 Evolution of the Psychological States Underlying U.S. Presidential Discourse

4.1.1 Authenticity

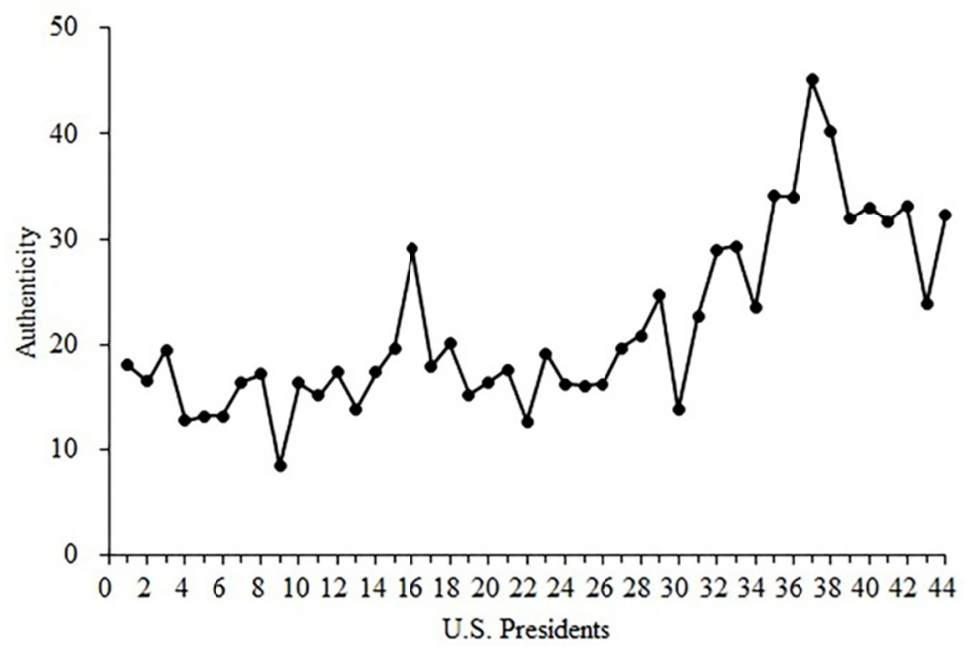

Figure 1. Evolution of authenticity in U.S. Presidential discourse. The numbers on the horizontal axis represent the codes assigned to the U.S. presidents (only even numbers are shown to save space)

As Figure 1 suggests, the general trend is that authenticity is on the increase in U.S. presidential discourse over the past 230 years. This trend is especially conspicuous from the 1920 s to the 1970 s (roughly from the 30th president Calvin Coolidge to the 37th president Richard Nixon). The lowest and highest levels of authenticity appeared respectively when the 9th president William Henry Harrison (1841) and President Richard Nixon were in office. Starting from Nixon, however, authenticity levels began to decrease steadily.

\subsubsection{Affect}

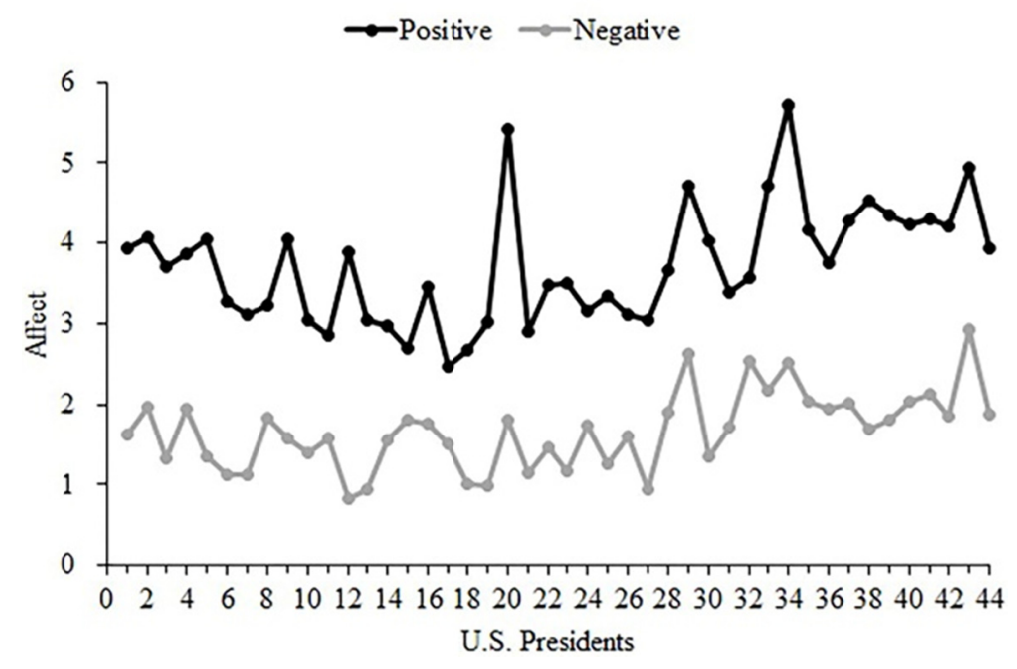

Figure 2. Evolution of affect in U.S. Presidential discourse

Figure 2 suggests that overall, positive emotions have invariably outweighed negative emotions in U.S. presidential discourse. In the long term, both positive and negative emotions seem to be fairly stable, though there are some obvious fluctuations in different time periods. The fluctuations in both positive and negative emotions follow a similar trend, often increasing or decreasing at the same time. Three periods stand out in 
particular: in the discourse of the 20th president James A. Garfield (1881), there was a sharp increase in both positive and negative emotions; from the early 1900s to the late 1920s (roughly from the 27th president William Howard Taft to the 30th president Calvin Coolidge), a rise appeared in both positive and negative emotions; from the 1940 s to 1960 s (roughly from the 33rd president Harry Truman to the 35th president John F. Kennedy), the rise of positive emotions was particularly salient.

4.1.3 Time Orientation

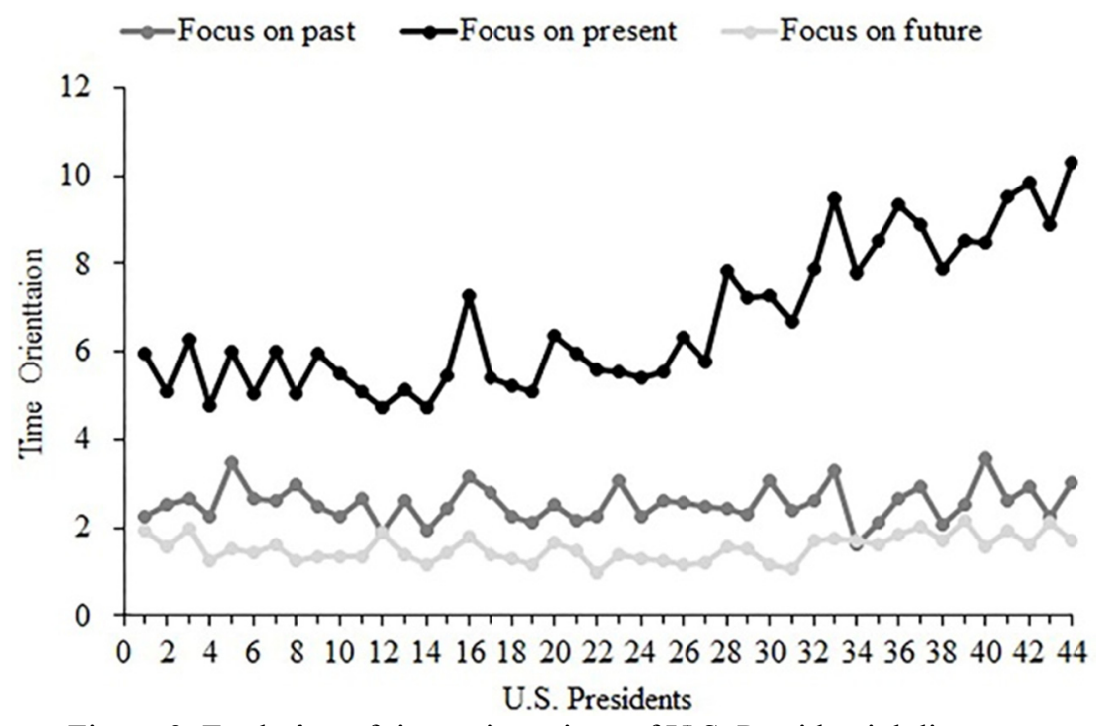

Figure 3. Evolution of time orientations of U.S. Presidential discourse

Figure 3 suggests that overall, the discourse of "focus on present" far outweighs the discourse of "focus on future", which outweighs the discourse of "focus on past". From a diachronic perspective, the U.S. presidents show an increasing emphasis on the present, while attention paid to the past and the future is quite stable across different time periods. Regarding "focus on present" in particular, increase on this front is particularly strong starting from the early 1930s (roughly from the 31 st U.S. president Herbert Hoover).

\subsection{Check of Significant Difference Between the Psychological States Underlying U.S. Presidential Discourse in Different Parties}

To see if the same trend holds with presidents from different political parties, we chose the corpora from 31 U.S presidents from Franklin Pierce to Barack Obama. The reason for not choosing the corpora of all 44 presidents is that in the early years of U.S. history, there was much disarray in the existence of and distinction between different political parties. And the co-existence of the Democratic Party and the Republican Party, which constitute the two major parties in the U.S., only began to become stable when Franklin Pierce was president, as can be seen in Appendix A.

First, we aimed to identify if any significant difference exists between the presidents of the two parties in terms of these three psychological states. Based on the LIWC indices in Appendix B, a series of independent samples t-test were performed to check this possibility. The results are presented in Table 1 as follows.

Table 1. Partisan differences in the three psychological constructs

\begin{tabular}{|c|c|c|c|}
\hline \multirow[t]{2}{*}{ Party } & \multicolumn{2}{|c|}{ Authenticity } & \multirow[t]{2}{*}{ Sig. } \\
\hline & $\mathrm{N}$ & $\mathrm{M}(\mathrm{SD})$ & \\
\hline Democratic & 13 & $23.78(8.85)$ & \multirow{2}{*}{$.63 *$} \\
\hline Republican & 18 & $25.27(7.86)$ & \\
\hline
\end{tabular}




\begin{tabular}{|c|c|c|c|c|c|}
\hline \multirow[t]{2}{*}{ Party } & \multicolumn{4}{|l|}{ Affect } & \multirow[t]{2}{*}{ Sig. } \\
\hline & \multirow{2}{*}{$\begin{array}{l}\text { Affect } \\
\text { Positive }\end{array}$} & $\mathrm{N}$ & \multicolumn{2}{|c|}{$\mathrm{M}(\mathrm{SD})$} & \\
\hline Democratic & & 13 & \multicolumn{2}{|c|}{$3.58(0.69)$} & \multirow[t]{2}{*}{$.27 *$} \\
\hline Republican & \multirow{3}{*}{ Negative } & 18 & & $0.90)$ & \\
\hline Democratic & & 13 & & (0.33) & \multirow[t]{2}{*}{$.48^{*}$} \\
\hline Republican & & 18 & & $0.59)$ & \\
\hline \multirow{2}{*}{ Party } & \multicolumn{4}{|l|}{ Time Orientation } & \multirow[t]{2}{*}{ Sig. } \\
\hline & Time Orientation & & $\mathrm{N}$ & $\mathrm{M}(\mathrm{SD})$ & \\
\hline Democratic & \multirow[t]{2}{*}{ Focus on past } & & 13 & $2.57(0.38)$ & \multirow[t]{2}{*}{$.92 *$} \\
\hline Republican & & & 18 & $2.55(0.48)$ & \\
\hline Democratic & \multirow{2}{*}{\multicolumn{2}{|c|}{ Focus on present }} & 13 & $7.56(1.99)$ & \multirow[t]{2}{*}{$.35 *$} \\
\hline Republican & & & 18 & $6.98(1.36)$ & \\
\hline Democratic & \multirow[t]{2}{*}{ Focus on future } & & 13 & $1.56(0.30)$ & \multirow[t]{2}{*}{$.69 *$} \\
\hline Republican & & & 18 & $1.52(0.32)$ & \\
\hline
\end{tabular}

*Note. The difference is significant at the 0.05 level $(p<.05)$.

As Table 1 suggests, there was no significant difference between the Democratic presidents and the Republican presidents in their discourse in terms of authenticity $(p=.63)$. Nor was there a significant difference between them in terms of positive $(\mathrm{p}=.27)$ and negative emotions $(\mathrm{p}=.48)$. Similarly, no significant difference was observed in focus on past $(\mathrm{p}=.92)$, focus on present $(\mathrm{p}=.35)$, or focus on future $(\mathrm{p}=.69)$.

\subsection{Similarities and Differences Between the Psychological States Underlying U.S. Presidential Discourse in Different Parties}

The independent samples t-test results showed no significant difference for all three psychological states. However, these results must be interpreted with caution. They may indicate that similarities exist between the presidents from the two different parties, or they may conceal some minor differences that indeed exist but did not become statistically significant. To delve deeper into the possible similarities and differences, the same LIWC indices used for the t-tests were used in this section to visualize the trend of the discourse evolution in each party, and they are put in the same scale for analysis.

\subsubsection{Authenticity}

As Figure 4 suggests, authenticity levels are on a steady increase in the discourse of Democratic presidents starting from the 1880s (the 22nd president Grover Cleveland), with little variation in the process. In contrast, the discourse of Republican presidents witnessed greater variation, increasing steadily from the 1920s (the 30th president Calvin Coolidge) until it starts to decrease from the 1970s (the 38th president Gerald Ford). The authenticity levels of both Democratic and Republican presidents decrease from the 1850s to the 1890s (roughly from the 15 th president to the 20 th president).

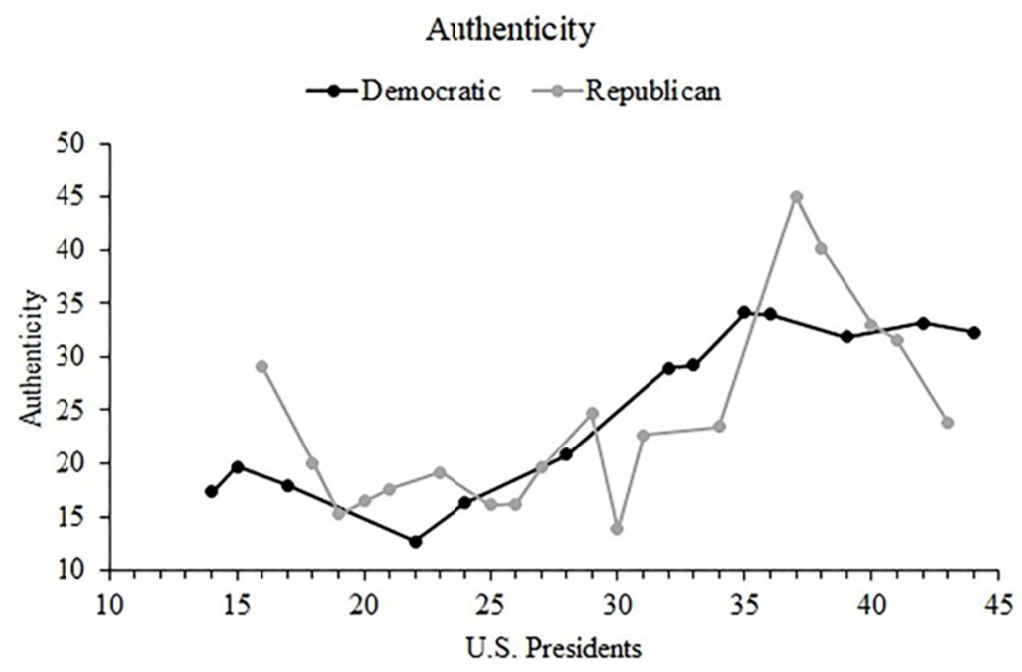

Figure 4. Evolution of authenticity levels in different parties. The numbers on the horizontal axis represent the codes assigned to the presidents from the two parties 


\subsubsection{Affect}
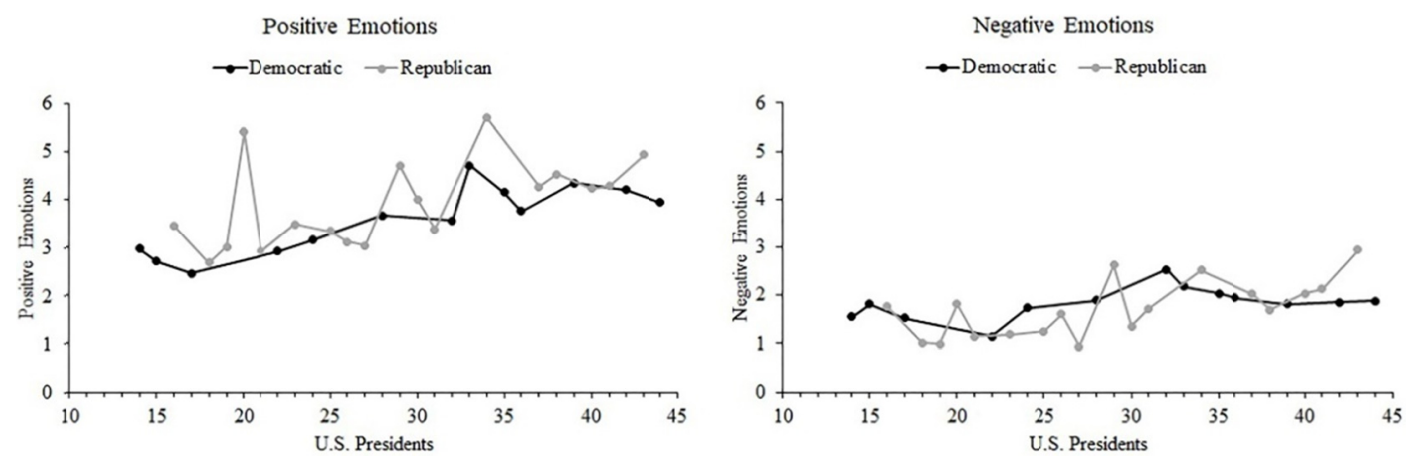

Figure 5. Evolution of affect in different parties

As Figure 5 indicates, both Democratic and Republican presidents display more positive emotions than negative emotions on the whole. The evolution of positive and negative emotions in the two political parties witnesses a similar trajectory. In terms of Democratic presidents, positive emotions are on a steady increase since almost the beginning, while negative emotions remain stable across different time periods. In terms of Republican presidents, positive emotions are characterized by a high level of variation, alternating between regular intervals of increase and decrease. In contrast, negative emotions are characterized by smaller variation and a slight uptick on the whole.

\subsubsection{Time Orientation}
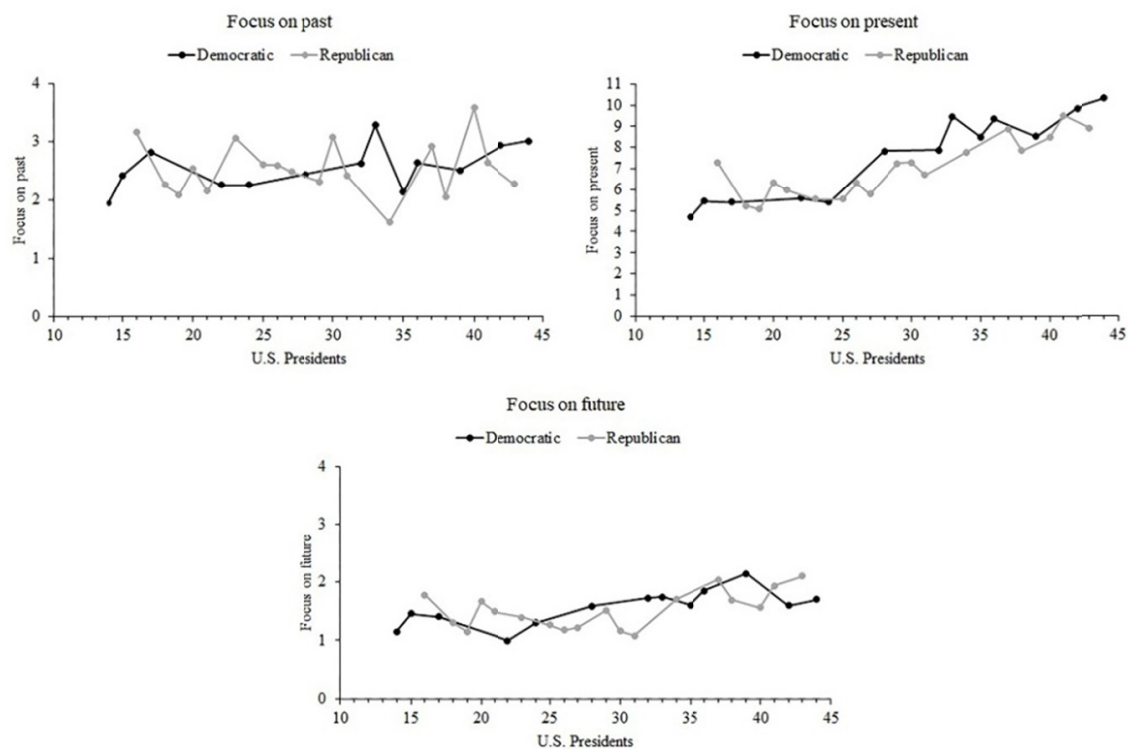

Figure 6. Evolution of time orientation in different parties

As Figure 6 suggests, in both Democratic and Republican presidents, the discourse of "focus on present" in presidential discourse outweighs the discourse of "focus on past", which outweighs the discourse of "focus on future". The discourse of "focus on present" is on a steady increase in presidents' discourse in both parties. "Focus on past" and "focus on future", in comparison, remain stable on the whole, but witness greater variation in different presidents. With respect to "focus on past" in particular, Republican presidents display greater variation than Democratic presidents in their discourse.

\section{Discussion}

\subsection{Trajectory of Psychological States Underlying U.S. Presidential Discourse on the Whole}

Our results indicate that on the whole, authenticity is increasing in the discourse of U.S. presidents. Although no 
previous study has taken a diachronic perspective on this psychological state, some studies have indirectly measured other relevant constructs, such as lying and deception, which can be seen as the antithesis of authenticity. These studies have shown that deception is a recurring theme in presidential discourse, often incurred by social or political circumstances (Duran, Hall, Mccarthy, \& Mcnamara, 2010; Wilson, 2015). This is consistent with the general view among the public that all politicians tell lies, at least to some extent. However, the results in this study suggest a different and perhaps surprising situation where the U.S. presidents are increasingly authentic. One possible reason is that the presidency itself has become increasingly public, in which case the presidents are required by their job to connect with the people (Lim, 2008). Therefore, to win the trust and support of the people, they have to exude greater authenticity, at least do so in public.

In terms of affect, this study shows that positive emotions have consistently outweighed negative emotions in U.S. presidential discourse, and that both positive and negative emotions are stable on the whole in U.S. presidential discourse. Some of the variations that occurred in different time periods seem especially conspicuous. However, a closer look at the data indicates that these deviations from the general trend may have been due to the small corpus size, as is the case with the 20th president James A. Garfield, who only served for one year (1881), and the 29th president Warren G. Harding, who only served for two years (1921-1923). When they are excluded from the other Republican presidents, it is clear that the both positive and negative emotions are stable in the long run, with the former outweighing the latter. These results can serve as a complement to recent studies on presidential discourse, which has been shown to become more negative, especially regarding President Trump (Liu \& Lei, 2018; Savoy, 2018). The recent rise of populism may have been one possible factor that contributed to this phenomenon, as a country-first narrative breeds a tendency to adopt a negative view towards other countries in an increasingly globalized world. And with more leaders bearing similar characteristics as Trump taking office, such a negative tendency may go beyond the U.S. to shape presidential discourse in other parts of the world as well.

The general trend regarding time orientation indicates a strong preference for "focus on present" discourse. This is not surprising given that the present is always of paramount importance in politics. In presidential elections, for example, political candidates who are a member of the ruling party tend to portray the status quo in a positive light and lay out an agenda for continuing such prosperity, thus turning the present into a strategic means to create a good impression on the public. Also, in electoral campaigns, the public is craving for solutions to their everyday problems, which are of immediate concern to their welfare. The candidates would have to address such questions as they arise. Similarly, when a president is in office, many of the problems he faces are happening in the moment, thus relating directly to the temporal context of the event. When a speech or address is delivered, it certainly reflects the "present" nature of the discourse that is produced.

\subsection{Trajectory of Psychological States Underlying U.S. Presidential Discourse in Different Parties}

As the two major political parties in the U.S., the Democratic Party and the Republican Party differ substantially in various aspects, but they are also similar in some common areas. The results in this study mainly reflect these similarities and differences in how the presidents affiliated with these two parties construct their discourse from a psychological perspective.

In terms of authenticity, the discourse of the Democratic presidents is shown to be on a steady increase on the whole. As no previous research has linked party affiliation to authenticity in discourse, this study may be the first of its kind to provide some initial evidence on this front. To explain this connection, it could be hypothesized that the ideologies, stances and ideals of the Democratic Party may predispose its presidential candidates or incumbent presidents toward more authentic discourse. Specifically, the Democratic Party has long labelled itself as the more progressive one, with greater tolerance for ethnic diversity and more emphasis on gender equality (Wilson, 2015). Such a liberal attitude towards social issues may thus shatter the burdens posed by traditional political constraints. Among the Republican presidents, however, authenticity began to decrease steadily from the 37th president Richard Nixon. This is not surprising that given the magnitude of the Watergate scandal and its political implications, subsequent Republican presidents are often compelled to conceal or distort their opinions on this topic to avoid political blunders. And the long-lasting influence of this scandal may have, in one way or another, shaped the norm of political discourse in the Party in general.

Regarding both affect and time orientation, the Democratic presidents and the Republican presidents are largely the same, in agreement with the overall trend. In terms of affect, neither positive nor negative emotions show obvious changes in the long run. This suggests that the emotional tone underlying U.S. presidential discourse remains constant, and party affiliation does not have an impact on emotional tone. The small fluctuations in different time periods are likely the result of the particular social context at play, where different emotional tones 
reflect changing social realities. In terms of time orientation, "focus on present" also constitutes the major focus of attention in presidential discourse regardless of the presidents' partisan background. The need of the electorate to have their immediate concerns addressed and the job of the presidency could have been the principal contributor to this trend, which is largely resistant to partisan influence.

\section{Conclusion}

This study investigated the evolution of three psychological states (authenticity, affect, and time orientation) underlying U.S. presidential discourse over 230 years. Based on one of the most comprehensive corpora of presidential discourse, namely, different types of speech transcripts of 44 U.S. presidents, LIWC 2015 was utilized to generate quantitative indices of the three psychological states. Further analysis was performed by visualizing these indices to illuminate their evolution across U.S. presidential history as a whole, and in two major political parties separately. The results showed that, 1) overall, authenticity level is on a steady increase in U.S. presidential discourse; 2) in the presidents' speeches, positive emotions invariably outweigh negative emotions, and both types of emotion remain relatively constant in the long run; 3) the discourse of "focus on present" consistently outweigh the discourse of "focus on future", which outweighs the discourse of "focus on past". Subsidiary analysis according to the presidents' party affiliation further complemented these results. A series of independent samples t-test initially suggested that there was no statistically significant difference between Democratic and Republican presidents in all the three psychological states. However, subsequent visualization of the LIWC indices revealed that, while party affiliation indeed did not serve to differentiate the presidents, putting the discourse of the presidents on a common scale better detected their similarities, and in some cases, helped to uncover differences that were not accounted for using significance values. These differences were mainly reflected in the construct of "authenticity", with authenticity levels on a steady increase among the Democratic presidents but decreasing in recent years among the Republican presidents.

Despite these findings, some of the limitations of this study must be addressed. First, some results from this study must be interpreted with caution, especially concerning those presidents who served in office for less than a four-year term or even less than a year. Because the corpus size of their discourse is comparatively small, they are likely to have influenced the results. Second, due to the scope of this study, only three psychological states were measured. Future studies may build upon comprehensive models in psychology to provide a panoramic view of the evolutionary process.

\section{Acknowledgments}

The authors gratefully acknowledge the research project supported by the Zhejiang Federation of Humanities and Social Sciences Circles (Survey Project).

\section{References}

Ahmadian, S., Azarshahi, S., \& Paulhus, D. L. (2017). Explaining Donald Trump via communication style: Grandiosity, informality, and dynamism. Personality and Individual Differences, 107, 49-53. https://doi.org/10.1016/j.paid.2016.11.018

Benoit, W. (2006). President Bush's image repair effort on Meet the Press: The complexities of defeasibility. Journal of Applied Communication Research, 34(3), 285-306. https://doi.org/10.1080/00909880600771635

Berisha, V., Wang, S., Lacross, A., \& Liss, J. (2015). Tracking discourse complexity preceding Alzheimer's disease diagnosis: A case study comparing the press conferences of presidents Ronald Reagan and George Herbert Walker Bush. Journal of Alzheimer's Disease, 45(3), 959-963. https://doi.org/10.3233/JAD-142763

Biria, R., \& Mohammadi, A. (2012). The socio-pragmatic functions of inaugural speech: A critical discourse $\begin{array}{llll}\text { analysis approach. Journal of } & \text { 1290-1302. }\end{array}$ https://doi.org/10.1016/j.pragma.2012.05.013

Bradshaw, S. C., Coe, K., \& Neumann, R. (2014). Newspaper attention to major presidential addresses: A reexamination of conceptualizations, predictors, and effects. Communication Reports, 27(1), 53-64. https://doi.org/10.1080/08934215.2013.858760

Chen, J., \& Hu, J. (2018). Enhancing L2 learners' critical thinking skills through a connectivism-based intelligent learning system. International Journal of English Linguistics, 8(6), 12-21. https://doi.org/10.5539/ijel.v8n6p12

Chen, J., Zhang, Y., Wei, Y., \& Hu, J. (2019). Discrimination of the contextual features of top performers in scientific literacy using a machine learning approach. Research in Science Education. Retrieved from https://rdcu.be/btN56. https://doi.org/10.1007/s11165-019-9835-y 
Chen, X. L., Yan, Y. L., \& Hu, J. (2019). A corpus-based study of Hillary Clinton's and Donald Trump's linguistic styles. International Journal of English Linguistics, 9(3), 13-22. https://doi.org/10.5539/ijel.v9n3p13

Choma, B. L., \& Hanoch, Y. (2017). Cognitive ability and authoritarianism: Understanding support for Trump and Clinton. Personality and Individual Differences, 106, 287-291. https://doi.org/10.1016/j.paid.2016.10.054

Cichocka, A., Bilewicz, M., Jost, J. T., Marrouch, N., \& Witkowska, M. (2016). On the grammar of politics -or why conservatives prefer nouns. Political Psychology, 37(6), 799-815. https://doi.org/10.1111/pops.12327

Coutanche, M. N., \& Paulus, J. P. (2018). An empirical analysis of popular press claims regarding linguistic change in President Donald J. Trump. Frontiers in Psychology, 9, 2311. https://doi.org/10.3389/fpsyg.2018.02311

Dunmire, P. L. (2005). Pre-empting the future: Rhetoric and ideology of the future in political discourse. Discourse \& Society, 16(4), 481-513. https://doi.org/10.1177/0957926505053052

Duran, N. D., Hall, C., Mccarthy, P. M., \& Mcnamara, D. S. (2010). The linguistic correlates of conversational deception: Comparing natural language processing technologies. Applied Psycholinguistics, 31(03), 439462. https://doi.org/10.1017/s0142716410000068

Dyson, S. B., \& Preston, T. (2006). Individual characteristics of political leaders and the use of analogy in foreign policy decision making. Political Psychology, 27(2), 265-288. https://doi.org/10.1111/j.1467-9221.2006.00006.x

Field, P. S. (2011). Abraham Lincoln and the first-person plural: A study in language and leadership. American Nineteenth Century History, 12(1), 49-75. https://doi.org/10.1080/14664658.2011.559748

Flint, C., Adduci, M., Chen, M., \& Chi, S. H. (2009). Mapping the dynamism of the United States' geopolitical code: The geography of the state of the union speeches, 1988-2008. Geopolitics, 14(4), 604-629. https://doi.org/10.1080/14650040802693929

Gilmore, J. (2014). Translating American exceptionalism: Comparing presidential discourse about the United States at home and abroad. International Journal of Communication, 8(1), 2416-2437. Retrieved from https://ijoc.org/index.php/ijoc/article/viewFile/2336/1263

Halmari, H. (2008). On the language of the Clinton-Dole presidential campaign debates: General tendencies and successful strategies. Journal of Language and Politics, 7(2), 247-270. https://doi.org/10.1075/jlp.7.2.04hal

Hodge, R., \& Kress, G. (1993). Language as ideology (2nd ed.). London, England: Routledge.

Hu, J., \& Wei, Y. (2018). The centrality of creativity: A new perspective on English language teaching. English Today, 35(2), 60-62. https://doi.org/10.1017/S0266078418000299

Jin, Y., Li, B., Chen, N., Li, X., \& Hu, J. (2015). The discrimination of learning styles by bayes-based statistics: An extended study on ILS system. Control and Intelligent Systems, 43(2), 68-75. https://doi.org/10.2316/Journal.201.2015.2.201-2666

Jordan, K. N., Pennebaker, J. W., \& Ehrig, C. (2018). The 2016 U.S. presidential candidates and how people tweeted about them. Sage Open, 8(3), 1-8. https://doi.org/10.1177/2158244018791218

Jordan, K. N., Sterling, J., Pennebaker, J. W., \& Boyd, R. L. (2019). Examining long-term trends in politics and culture through language of political leaders and cultural institutions. PNAS, 116(9), 3476-3481. https://doi.org/10.1073/pnas.1811987116

Kubat, M., \& Cech, R. (2016). Quantitative analysis of US presidential inaugural addresses. Glottometrics, 34, $14-27$.

Lim, E. T. (2008). The anti-intellectual presidency: The decline of presidential rhetoric from George Washington to George W. Bush. Madison Avenue, NY: Oxford University Press. https://doi.org/10.1093/acprof:oso/9780195342642.001.0001

Liu, D. L., \& Lei, L. (2018). The appeal to political sentiment: An analysis of Donald Trump's and Hillary Clinton's speech themes and discourse strategies in the 2016 US presidential election. Discourse Context \& Media, 25, 143-152. https://doi.org/10.1016/j.dcm.2018.05.001

Moen, M. C. (1988). The political agenda of Ronald Reagan: A content analysis of the State of the Union messages. Presidential Studies Quarterly, 18(4), 775-785. https://doi.org/10.2139/ssrn.2459130 
Newman, M. L., Pennebaker, J. W., Berry, D. S., \& Richards, J. M. (2003). Lying words: Predicting deception from linguistic styles. Personality and Social Psychology Bulletin, 29, 665-675. https://doi.org/10.1177/0146167203029005010

O’Connell, D. C., Kowal, S., Sabin, E. J., Lamia, J. F., \& Dannevik, M. (2010). Start-up rhetoric in eight speeches of Barack Obama. Journal of Psycholinguistic Research, 39(5), 393-409. https://doi.org/10.1007/s10936-010-9147-x

Panagopoulos, C. (2011). Polls and elections: Firing back: Out-party responses to presidential State of the Union $\begin{array}{lllll}\text { addresses, 1966-2006. Presidential Studies } & \text { Quarterly, 41(3), 604-617. }\end{array}$ https://doi.org/10.1111/j.1741-5705.2011.03889.x

Pennebaker, J. W., Boyd, R. L., Jordan, K., \& Blackburn, K. (2015). The development and psychometric properties of LIWC 2015. Retrieved from https://www.liwc.net/LIWC2007LanguageManual.pdf

Ponterotto, D. (2018). Hedging in political interviewing: When Obama meets the press. Pragmatics and Society, 9(2), 175-207. https://doi.org/10.1075/ps.15030.pon

Reyes, A. (2011). Strategies of legitimization in political discourse: From words to actions. Discourse \& Society, 22(6), 781-807. https://doi.org/10.1177/0957926511419927

Savoy, J. (2017). Analysis of the style and the rhetoric of the American presidents over two centuries. Glottometrics, 38, 55-76.

Savoy, J. (2018). Trump's and Clinton's style and rhetoric during the 2016 presidential election. Journal of Quantitative Linguistics, 25(2), 168-189. https://doi.org/10.1080/09296174.2017.1349358

Schoor, C. (2017). In the theater of political style: Touches of populism, pluralism and elitism in speeches of politicians. Discourse \& Society, 28(6), 657-676. https://doi.org/10.1177/0957926517721082

Slatcher, R. B., Chung, C. K., Pennebaker, J. W., \& Stone, L. D. (2007). Winning words: Individual differences in linguistic style among U.S. presidential and vice-presidential candidates. Journal of Research in Personality, 41(1), 63-75. https://doi.org/10.1016/j.jrp.2006.01.006

Thoemmes, F. J., \& Conway, L. G. (2007). Integrative complexity of 41 U.S. presidents. Political Psychology, 28(2), 193-226. https://doi.org/10.1111/j.1467-9221.2007.00562.x

Wasike, B. (2017). Charismatic rhetoric, integrative complexity and the U.S. presidency: An analysis of the State of the Union Address (SOTU) from George Washington to Barack Obama. The Leadership Quarterly, 28(6), 812-826. https://doi.org/10.1016/j.leaqua.2017.04.002

Wei, Y., Yang, Q., Chen, J., \& Hu, J. (2018). The exploration of a machine learning approach for the assessment of learning styles changes. Mechatronic Systems and Control, 46(3), 121-126. https://doi.org/10.2316/Journal.201.2018.3.201-2979

Widmer, T. (2006). American speeches: Political oratory from Abraham Lincoln to Bill Clinton. New York, NY: Library of America.

Wilson, J. (2015). Talking with the president: The pragmatics of presidential language. Madison Avenue, NY: Oxford University Press. https://doi.org/10.1093/acprof:oso/9780199858804.001.0001

Xiao, Y., Li, Y., \& Hu, J. (2019). Construction of the Belt and Road Initiative in Chinese and American media: A critical discourse analysis based on self-built corpora. International Journal of English Linguistics, 9(3), 68-77. https://doi.org/10.5539/ijel.v9n3p68 


\section{Appendix A}

Profile of the speech corpora of 44 U.S. presidents

\begin{tabular}{|c|c|c|c|c|}
\hline Code & President & Party Affiliation & Term & Word Count \\
\hline 1 & George Washington & Unaffiliated & $1789-1797$ & 31643 \\
\hline 2 & John Adams & Federalist & $1797-1801$ & 14672 \\
\hline 3 & Thomas Jefferson & Democratic-Republican & $1801-1809$ & 40149 \\
\hline 4 & James Madison & Democratic-Republican & $1809-1817$ & 36049 \\
\hline 5 & James Monroe & Democratic-Republican & $1817-1825$ & 49960 \\
\hline 6 & John Quincy Adams & Democratic-Republican & $1825-1829$ & 36472 \\
\hline 7 & Andrew Jackson & Democratic & $1829-1837$ & 157535 \\
\hline 8 & Martin Van Buren & Democratic & $1837-1841$ & 64747 \\
\hline 9 & William Henry Harrison & Whig & 1841 & 8465 \\
\hline 10 & John Tyler & Whig & $1841-1845$ & 69471 \\
\hline 11 & James K. Polk & Democratic & $1845-1849$ & 104267 \\
\hline 12 & Zachary Taylor & Whig & $1849-1850$ & 11368 \\
\hline 13 & Millard Fillmore & Whig & $1850-1853$ & 39392 \\
\hline 14 & Franklin Pierce & Democratic & $1853-1857$ & 63448 \\
\hline 15 & James Buchanan & Democratic & $1857-1861$ & 80883 \\
\hline 16 & Abraham Lincoln & Republican & $1861-1865$ & 95643 \\
\hline 17 & Andrew Johnson & Democratic & $1865-1869$ & 98806 \\
\hline 18 & Ulysses S. Grant & Republican & $1869-1877$ & 103060 \\
\hline 19 & Rutherford B. Hayes & Republican & $1877-1881$ & 67474 \\
\hline 20 & James A. Garfield & Republican & 1881 & 2980 \\
\hline 21 & Chester Arthur & Republican & $1881-1885$ & 49590 \\
\hline 22 & Grover Cleveland & Democratic & $1885-1889$ & 66095 \\
\hline 23 & Benjamin Harrison & Republican & $1889-1893$ & 76363 \\
\hline 24 & Grover Cleveland & Democratic & $1893-1897$ & 89458 \\
\hline 25 & William McKinley & Republican & $1897-1901$ & 92318 \\
\hline 26 & Theodore Roosevelt & Republican & $1901-1909$ & 196692 \\
\hline 27 & William Howard Taft & Republican & $1909-1913$ & 117594 \\
\hline 28 & Woodrow Wilson & Democratic & $1913-1921$ & 80123 \\
\hline 29 & Warren G. Harding & Republican & $1921-1923$ & 28752 \\
\hline 30 & Calvin Coolidge & Republican & $1923-1929$ & 74333 \\
\hline 31 & Herbert Hoover & Republican & $1929-1933$ & 87888 \\
\hline 32 & Franklin D. Roosevelt & Democratic & $1933-1945$ & 132082 \\
\hline 33 & Harry S. Truman & Democratic & $1945-1953$ & 36954 \\
\hline 34 & Dwight D. Eisenhower & Republican & $1953-1961$ & 18097 \\
\hline 35 & John F. Kennedy & Democratic & $1961-1963$ & 136196 \\
\hline 36 & Lyndon B. Johnson & Democratic & $1963-1969$ & 231949 \\
\hline 37 & Richard Nixon & Republican & 1969-1974 & 66482 \\
\hline 38 & Gerald Ford & Republican & 1974-1977 & 40446 \\
\hline 39 & Jimmy Carter & Democratic & $1977-1981$ & 70388 \\
\hline 40 & Ronald Reagan & Republican & 1981-1989 & 196553 \\
\hline 41 & George Bush & Republican & 1989-1993 & 71160 \\
\hline 42 & Bill Clinton & Democratic & 1993-2001 & 144580 \\
\hline 43 & George W. Bush & Republican & 2001-2009 & 107737 \\
\hline \multirow[t]{2}{*}{44} & Barack Obama & Democratic & 2009-2016 & 199211 \\
\hline & Total & & & 3587525 \\
\hline
\end{tabular}




\section{Appendix B}

LIWC indices for the three psychological states of 44 U.S. presidents

\begin{tabular}{|c|c|c|c|c|c|c|}
\hline \multirow[t]{3}{*}{ Code } & \multirow[t]{3}{*}{ Authenticity } & \multicolumn{2}{|l|}{ Affect } & \multicolumn{3}{|c|}{ Time Orientation } \\
\hline & & Positive & Negative & Focus on Past & Focus on Present & Focus on Future \\
\hline & & Emotion & Emotion & & & \\
\hline 1 & 18.03 & 3.94 & 1.62 & 2.28 & 5.96 & 1.94 \\
\hline 2 & 16.55 & 4.08 & 1.98 & 2.55 & 5.09 & 1.58 \\
\hline 3 & 19.48 & 3.7 & 1.34 & 2.68 & 6.26 & 2 \\
\hline 4 & 12.86 & 3.87 & 1.94 & 2.25 & 4.75 & 1.26 \\
\hline 5 & 13.22 & 4.05 & 1.34 & 3.48 & 6.01 & 1.54 \\
\hline 6 & 13.26 & 3.28 & 1.13 & 2.66 & 5.04 & 1.43 \\
\hline 7 & 16.42 & 3.11 & 1.13 & 2.6 & 5.99 & 1.62 \\
\hline 8 & 17.23 & 3.22 & 1.84 & 2.98 & 5.07 & 1.23 \\
\hline 9 & 8.39 & 4.04 & 1.58 & 2.47 & 5.95 & 1.35 \\
\hline 10 & 16.33 & 3.04 & 1.39 & 2.26 & 5.48 & 1.34 \\
\hline 11 & 15.15 & 2.86 & 1.59 & 2.66 & 5.1 & 1.35 \\
\hline 12 & 17.34 & 3.88 & 0.83 & 1.88 & 4.72 & 1.87 \\
\hline 13 & 13.95 & 3.03 & 0.95 & 2.65 & 5.13 & 1.39 \\
\hline 14 & 17.36 & 2.98 & 1.55 & 1.96 & 4.71 & 1.16 \\
\hline 15 & 19.68 & 2.71 & 1.82 & 2.43 & 5.45 & 1.46 \\
\hline 16 & 29.05 & 3.45 & 1.77 & 3.17 & 7.27 & 1.78 \\
\hline 17 & 18 & 2.46 & 1.52 & 2.83 & 5.4 & 1.41 \\
\hline 18 & 20.04 & 2.69 & 1.01 & 2.26 & 5.23 & 1.3 \\
\hline 19 & 15.24 & 3.01 & 0.98 & 2.1 & 5.07 & 1.15 \\
\hline 20 & 16.46 & 5.42 & 1.81 & 2.54 & 6.35 & 1.67 \\
\hline 21 & 17.64 & 2.92 & 1.14 & 2.16 & 5.98 & 1.49 \\
\hline 22 & 12.7 & 3.49 & 1.46 & 2.26 & 5.59 & 1 \\
\hline 23 & 19.15 & 3.49 & 1.18 & 3.08 & 5.55 & 1.4 \\
\hline 24 & 16.3 & 3.15 & 1.74 & 2.26 & 5.4 & 1.3 \\
\hline 25 & 16.12 & 3.34 & 1.25 & 2.61 & 5.55 & 1.27 \\
\hline 26 & 16.24 & 3.12 & 1.6 & 2.6 & 6.32 & 1.18 \\
\hline 27 & 19.63 & 3.03 & 0.94 & 2.49 & 5.8 & 1.22 \\
\hline 28 & 20.85 & 3.66 & 1.89 & 2.45 & 7.84 & 1.59 \\
\hline 29 & 24.68 & 4.72 & 2.63 & 2.32 & 7.24 & 1.52 \\
\hline 30 & 13.86 & 4.02 & 1.36 & 3.09 & 7.3 & 1.16 \\
\hline 31 & 22.71 & 3.38 & 1.72 & 2.41 & 6.7 & 1.09 \\
\hline 32 & 28.94 & 3.56 & 2.54 & 2.64 & 7.88 & 1.72 \\
\hline 33 & 29.28 & 4.72 & 2.18 & 3.29 & 9.46 & 1.75 \\
\hline 34 & 23.5 & 5.72 & 2.52 & 1.61 & 7.77 & 1.72 \\
\hline 35 & 34.1 & 4.16 & 2.04 & 2.14 & 8.5 & 1.61 \\
\hline 36 & 33.99 & 3.76 & 1.94 & 2.65 & 9.33 & 1.85 \\
\hline 37 & 45.1 & 4.27 & 2.03 & 2.93 & 8.89 & 2.04 \\
\hline 38 & 40.19 & 4.53 & 1.7 & 2.06 & 7.86 & 1.7 \\
\hline 39 & 31.9 & 4.35 & 1.81 & 2.52 & 8.54 & 2.14 \\
\hline 40 & 33 & 4.24 & 2.04 & 3.59 & 8.47 & 1.56 \\
\hline 41 & 31.63 & 4.29 & 2.12 & 2.64 & 9.5 & 1.94 \\
\hline 42 & 33.19 & 4.21 & 1.85 & 2.95 & 9.85 & 1.6 \\
\hline 43 & 23.8 & 4.94 & 2.94 & 2.28 & 8.88 & 2.11 \\
\hline 44 & 32.29 & 3.94 & 1.87 & 3.02 & 10.3 & 1.7 \\
\hline
\end{tabular}

\section{Copyrights}

Copyright for this article is retained by the author, with first publication rights granted to the journal.

This is an open-access article distributed under the terms and conditions of the Creative Commons Attribution license (http://creativecommons.org/licenses/by/4.0/). 